\title{
Clinical determinants of Lyme borreliosis, babesiosis, bartonellosis, anaplasmosis, and ehrlichiosis in an Australian cohort
}

This article was published in the following Dove Press journal:

International Journal of General Medicine

23 December 2014

Number of times this article has been viewed

Peter J Mayne

Laurieton Medical Centre, Laurieton, NSW, Australia
Correspondence: Peter J Mayne Laurieton Medical Centre, 89 Bold St Laurieton, NSW 2443, Australia Tel +6I 265599277

Fax +6I 265597344

Email laurietonmedical@gmail.com
Background: Borrelia burgdorferi is the causative agent of Lyme borreliosis. This spirochete, along with Babesia, Bartonella, Anaplasma, Ehrlichia, and the Rickettsia spp. are recognized tick-borne pathogens. In this study, the clinical manifestation of these zoonoses in Australia is described.

Methods: The clinical presentation of 500 patients over the course of 5 years was examined. Evidence of multisystem disease and cranial nerve neuropathy was sought. Supportive laboratory evidence of infection was examined.

Results: Patients from every state of Australia presented with a wide range of symptoms of disease covering multiple systems and a large range of time intervals from onset. Among these patients, 296 (59\%) were considered to have a clinical diagnosis of Lyme borreliosis and 273 (54\% of the 500) tested positive for the disease, the latter not being a subset of the former. In total, $450(90 \%)$ had either clinical evidence for or laboratory proof of borrelial infection, and the great majority of cases featured neurological symptoms involving the cranial nerves, thus mimicking features of the disease found in Europe and Asia, as distinct from North America (where extracutaneous disease is principally an oligoarticular arthritis). Only 83 patients $(17 \%$; number $[n]=492)$ reported never leaving Australia. Of the 500 patients, $317(63 \%)$ had clinical or laboratory-supported evidence of coinfection with Babesia or Bartonella spp. Infection with $A$. phagocytophilum was detected in three individuals, and Ehrlichia chaffeensis was detected in one individual who had never traveled outside Australia. In the cohort, 30 (11\%; $\mathrm{n}=279$ ) had positive rickettsial serology.

Conclusion: The study suggests that there is a considerable presence of borreliosis in Australia, and a highly significant burden of coinfections accompanying borreliosis transmission. The concept sometimes advanced of a "Lyme-like illness" on the continent needs to be re-examined as the clinical interplay between all these infections. Evidence is presented for the first report of endemic anaplasmosis and ehrlichiosis on the continent.

Keywords: Borrelia, Lyme disease, Babesia, Bartonella, Australia, humans

\section{Introduction}

The existence of human tick-borne disease (TBD) has been previously described in Australia by the author to comprise multiple zoonoses induced by the pathogens Borrelia, Babesia, Bartonella, Anaplasma, and Ehrlichia spp. ${ }^{1}$ Other arbobacteria infections sometimes found worldwide are Coxiella burnetii, Francisella tularensis, Yersinia pestis, and the Rickettsia sp., with the latter comprising significant infection on this continent and having three unique subspecies. ${ }^{1}$ Most grow intracellularly, but Borrelia sp. is also extracellular and $Y$. pestis is mainly extracellular. ${ }^{2}$ In this case series 
of 500 consecutive patients presenting between October 2010 and February 2014, either referred or self-initiated regarding the possibility of "Lyme disease", an analysis was done to define the clinical characteristics at the time of presentation of these zoonoses compared to those seen in North America, Europe, and Asia, as well as to quantify incidence figures. Patients attended from every state in Australia. In Australia, borrelial infection typically manifests with a neurological presentation, which follows the course seen in Europe and Asia, as discussed earlier. ${ }^{1}$ Australian endemic human babesiosis with $B$. microti has been reported clinically, serologically, and at the molecular level. ${ }^{1,3,4}$ There has been a recent nomenclature shift, with this piroplasm now classified as a Theileria sp. In this manuscript, the former nomenclature will be used. Babesiosis with $B$. duncani has been previously reported as an Australian endemic infection by this author. ${ }^{1}$ Herein, the first Australian human endemic Anaplasmataceae infections with A. phagocytophilum and E. chaffeensis are reported: three cases for the former and one for the latter pathogen. This is intended to show a complex interplay of symptoms and signs between these TBD infections, clinically necessitating a thorough assessment to be able to treat the diseases appropriately. Diagnosing borreliosis has previously been discussed, including the fact that North America singularly has a large proportion of mono or pauci arthritis characterized by extensive swelling, which can be migratory. ${ }^{1}$ This arthritic presentation is not seen in Australian borreliosis in this series. Also, it is important to reiterate that the involvement of a large number of cranial nerves will point the differential diagnoses at only borreliosis, bartonellosis, sarcoid, and Guillaine Barre disease. ${ }^{1}$ Amyloid should now be added to this list as a further causative factor, but there also appears to be a strong association with neuroborreliosis and sarcoidosis. ${ }^{5-13}$ The patient's clinical history and examination techniques used in diagnosing TBD at a clinical level are discussed and correlated to the level of laboratory-supported diagnosis that can be expected. Particular emphasis is given to diagnosing neuroborreliosis from a clinical perspective. Some early demographic and epidemiological data for this continent are presented.

\section{Materials and methods}

\section{Demographic and epidemiologic assessment}

The data from 500 patient records were analyzed using 55 parameters that were subdivided into demographic, epidemiological, and clinical findings (see Tables 1 and 2). A patient questionnaire was obtained prior to consultation to assess the likelihood of multisystemic disease and multiple
Table I Demographic and epidemiologic parameters extracted from the dataset

\begin{tabular}{llll}
\hline $\begin{array}{l}\text { Demographic, epidemiologic, } \\
\text { and clinical parameters }\end{array}$ & Number & Percentage & $\begin{array}{l}\text { Total } \\
\text { number }\end{array}$ \\
\hline Average age at presentation & 41 & & 500 \\
Average age at onset of illness & 35 & & 500 \\
Sex, female & 310 & 62 & 500 \\
Never left the country & 83 & 17 & 492 \\
Average illness length in years & 7.4 & & 343 \\
at time of presentation & & & \\
Tick bites recorded & 240 & 71 & 340 \\
\hline
\end{tabular}

cranial nerve abnormality. This was a truncated version of a symptom list from the Burrascano Lyme disease guidelines. ${ }^{14}$ Inquiry was made into tick attachment and any associated reddening or swelling of the skin. A travel history outside Australia was sought from the perspective of ever going abroad or being born overseas.

\section{Clinical assessment}

Symptoms and signs of cranial nerve deficit were sought using a cranial nerve assessment tool (Table 3). This tool was refined over time. Signs were sought by physical examination. The peripheral nervous system was briefly reviewed, but it was generally not helpful in pinpointing TBD, except that a pathological upwards plantar response (Babinski sign) and hypothenar wasting were not uncommon, which are possible indicators of babesiosis. ${ }^{15}$ Particular note was made of large joint pain (hip, knee, shoulder, elbow, wrist, and ankle) with or without swelling compared to small joint pain in the hands, feet, spine, and jaw. The costochondral joints were checked for tenderness. Three psychological parameters in particular were sought: panic attacks lasting more than 30 minutes is associated with borreliosis; in addition, sudden bursts of anger and worsening obsessive compulsive behavior are both associated with bartonellosis. Certain investigation parameters were analyzed in three groups with testing performed at Australian Biologics Sydney (Table 4), IGeneX at Palo Alto, CA, USA (Table 5), and ancillary tests conducted at laboratories across Australia (Table 6; this table also shows single-photon emission computed tomography [SPECT] scans).

\section{Borrelia}

The patients' symptoms, signs, and examination were checked for neurological problems (as indicated in Table 3), as well as for multisystemic problems over the timeline of the disease (as previously discussed) to form a clinical opinion of the likelihood of the disease based on the involvement of more than three cranial nerves and at least one other system. ${ }^{1}$ The 
Table 2 Clinical parameters extracted from the dataset

\begin{tabular}{llll}
\hline Clinical parameters extracted from the dataset & Incidence & Percentage & Number \\
\hline EM rash adequately described & 108 & 78 & 739 \\
Cranial nerve dysfunction & 355 & 71 & 500 \\
More than three cranial nerves involved & 296 & 59 & 500 \\
Cardiac problem of any description & 52 & 58 & 89 \\
Suspected postural orthostatic tachycardia syndrome & 48 & 54 & 52 \\
Gastrointestinal symptoms of any kind & 80 & 44 & 153 \\
Genitourinary symptoms & 68 & 36 & 153 \\
Dermopathy of any type & 55 & 6 & 153 \\
Morgellons evidenced by direct skin microscopy & 29 & 37 & 500 \\
Small joint pain & 57 & 1 & 153 \\
Large joint pain & 2 & 0 & 153 \\
Mono arthritis (documented illness in the United States) & 2 & 61 & 500 \\
Clinical borreliosis - more than three cranial nerves involved & 307 & 268 & 52 \\
Clinical babesiosis - specific babesiosis symptoms & 240 & 89 & 292 \\
Clinical bartonellosis - specific bartonellosis symptoms & & \\
\hline
\end{tabular}

Abbreviation: EM, erythema migrans.

history questionnaire was used to assess patients' symptoms in the first instance in all cases, and some points would require clarification during the consultation, which involved the use of the cranial nerve tool and multisystem review. If the review showed three or fewer cranial nerves involved, then it was determined that borreliosis was a possibility; however, laboratory testing needed to be relied upon for a diagnosis. For more than three cranial nerves involved, a clinical diagnosis of borreliosis or bartonellosis was made. At this juncture, it should also be stated that reliance was placed on a negative computed tomography $(\mathrm{CT})$ or magnetic resonance imaging (MRI) scan of the brain to exclude overt intracranial disease, and this was ordered if not done previously.

\section{Babesia and Bartonella}

Attention was also focused on blocks of symptoms in the patient questionnaire that typically occurred with these TBD coinfections (Table 7). The significant presence of more than just a few of these factors in recognized TBD illness is a harbinger for the presence of coinfection based on clinical grounds. Symptoms/signs that may indicate Babesia are tinnitus, chills, flushing, dysphagia, severe neurological disease, thirst, night sweats, chest wall or sternal pain, polydipsia, fatigue, severe nausea, malaise, fever, fine hemangiomas, hypothenar atrophy, papular or vesicular rash, petechiae, anemia, abnormal platelet counts, and the development of these symptoms during borreliosis therapy. ${ }^{15,16}$ Two European reviews are also helpful in understanding this disease from a clinical perspective. ${ }^{17,18}$ Symptoms/signs that may indicate Bartonella are brain fog, ice pick headaches, photophobia, tachycardia, bowel issues, tender subdermal masses (particularly of the neck, forearm, and ileotibial band), increased obsessive compulsive behavior, anxiety, endocarditis, retinitis, peripheral neuropathy, rapid relapse off antibiotics, immediate systemic illness following tick bite (within days), swollen joints, psychiatric issues, costal margin pain and tenderness, rapid mood shifts, and the development of these symptoms during Babesia therapy. ${ }^{15,16}$

\section{Anaplasma/Ehrlichia}

A. phagocytophilum and E. chaffeensis are the etiologic causes of anaplasmosis and ehrlichiosis, and they were formerly known as human granulocytic ehrlichiosis and human monocytic ehrlichiosis, respectively, indicating the white cell line implicated in each infection. ${ }^{1}$ The particular symptoms that may guide the diagnostician with these infections are, myalgia, tendon pain, extreme soft tissue tenderness, right upper quadrant pain, slumped posture, hepatomegaly, diaphoresis, muscle spasms, elevated liver enzymes (intrahepatic pattern) and, most importantly, a depressed white cell count. ${ }^{15,16}$ Acute infection can be lethal, and treatment must start on clinical suspicion with doxycycline before laboratory confirmation. However, when these TBDs are associated with borreliosis, there appears a much slower chronic and lingering infection with reports of extreme fatigue and feeling severely unwell. With not much in the way of distinctive symptoms, a high degree of suspicion is warranted. Testing is done by serology and polymerase chain reaction (PCR).

\section{Other infections}

Mycoplasma pneumoniae and Mycoplasma fermentans will lead to fatigue, fever, insomnia, headache, bowel issues, psychiatric disturbances, and arthritis (both large and 
Table 3 Cranial nerve assessment tool for neuroborreliosis and bartonellosis

\begin{tabular}{|c|c|c|}
\hline $\begin{array}{l}\text { Cranial } \\
\text { nerve }\end{array}$ & Reported symptoms & Examination \\
\hline I & Phantom smells & Anosmia partial/full \\
\hline I & Any loss of smell & \\
\hline I & Left or right & Which side \\
\hline 2 & & Visual acuity \\
\hline 2 & Loss of any part of vision & Visual fields \\
\hline 2 & Any floaters & Check patient's understanding \\
\hline 2 & Any loss of night vision & \\
\hline 3 & & Full pupil assessment \\
\hline 3 & & Focusing difficulty with small print \\
\hline 3 & Dilated pupil(s) & \\
\hline 3 & Double vision - directional & Diplopia - medial or upwards \\
\hline 3 & Drooping eyelids & Ptosis \\
\hline 4 & $\begin{array}{l}\text { Double vision - } \\
\text { downwards direction }\end{array}$ & Diplopia - downwards direction \\
\hline 6 & $\begin{array}{l}\text { Double vision - lateral } \\
\text { with weak affected eye }\end{array}$ & $\begin{array}{l}\text { Diplopia - lateral with weak } \\
\text { affected eye }\end{array}$ \\
\hline 5 & Facial pain & Facial pain trigeminal divisions \\
\hline 5 & & Loss of corneal reflex \\
\hline 5 & Taste changes & \\
\hline 5 & Dental pain & \\
\hline 5 & Jaw pain & \\
\hline 7 & Facial paralysis (Bell's palsy) & Facial paralysis (Bell's palsy) \\
\hline 7 & $\begin{array}{l}\text { Facial muscle weakness } \\
\text { or muscle twitching }\end{array}$ & $\begin{array}{l}\text { Facial muscle weakness or } \\
\text { muscle twitching }\end{array}$ \\
\hline 7 & & Test masseters \\
\hline 7 & & Mental reflex \\
\hline 8 & $\begin{array}{l}\text { Loss of hearing during } \\
\text { illness }\end{array}$ & \\
\hline 8 & $\begin{array}{l}\text { More sensitive to loud } \\
\text { sound or pain }\end{array}$ & \\
\hline 8 & Tinnitus & Tinnitus \\
\hline 8 & Vertigo & Vertigo, check on true meaning \\
\hline 8 & Imbalance & Imbalance \\
\hline 8 & & Rombergism \\
\hline 8 & & Nystagmus (rapid is affected side) \\
\hline 9 & Throat sore & \\
\hline 9 & Difficulty swallowing & \\
\hline 9 & & Elevates larynx swallowing \\
\hline 9 & & Gag reflex present \\
\hline 9 & Lack of saliva & \\
\hline 10 & $\begin{array}{l}\text { Neck pain around the } \\
\text { throat }\end{array}$ & \\
\hline 10 & Slurring of speech & Slurring of speech \\
\hline 10 & Mispronunciation & Mispronunciation \\
\hline 10 & $\begin{array}{l}\text { Rapid beating of the } \\
\text { heart or irregularity }\end{array}$ & $\begin{array}{l}\text { Rapid beating of the heart or } \\
\text { irregularity standing up quickly }\end{array}$ \\
\hline 10 & Feeling faint & Feeling faint \\
\hline 10 & & $\begin{array}{l}\text { Clinical evidence or suggestion } \\
\text { of POTS }\end{array}$ \\
\hline 11 & Cannot shrug shoulders & \\
\hline II & & SCM and trapezius strength \\
\hline 12 & $\begin{array}{l}\text { Difficulty with tongue } \\
\text { movements }\end{array}$ & $\begin{array}{l}\text { Tongue movement and strength } \\
\text { full }\end{array}$ \\
\hline 12 & Biting tongue & \\
\hline
\end{tabular}

Abbreviations: POTS, postural orthostatic tachycardia syndrome; SCM, sternocleidomastoid.
Table 4 Borreliosis and coinfection investigation parameters extracted from the data for $A B$

\begin{tabular}{llll}
\hline AB testing & Positives & Percentage & Number \\
\hline Borrelia & & & \\
Whole-blood PCR & $8 \mathrm{I}$ & 55 & 146 \\
Serum PCR & 18 & 58 & 31 \\
Urine PCR & 46 & 84 & 55 \\
Immunoblot IgM & 7 & 47 & 15 \\
Immunoblot IgG & 4 & 27 & 15 \\
Total immunoblot positive & 10 & 67 & 15 \\
ELISPOT LTT & 16 & 84 & 19 \\
AB Borrelia total positive testing & 127 & 59 & 216 \\
AB Borrelia total negative testing & 89 & 41 & 216 \\
Mycoplasma PCR positive & 30 & 43 & 69 \\
Mycoplasma fermentans PCR & 18 & 26 & 69 \\
Positive & & & \\
AB Chlamydia Pn PCR positive & 9 & 18 & 50
\end{tabular}

Abbreviations: $A B$, Australian Biologics; PCR, polymerase chain reaction; Ig, immunoglobulin; ELISPOT, enzyme-linked immunosorbent spot test; LTT, lymphocyte transformation test; Pn, pneumonia.

small joints) with joint swelling. ${ }^{16}$ M. fermentans can show a negative response to prior antibiotic use with tetracyclines and macrolides. Chlamydophila pneumoniae, formerly designated as Chlamydia pneumoniae (CPN), is a known cause of respiratory illness, but it may also cause widespread arthritic pains in patients with TBD, as can C. trachomatis. ${ }^{19}$ Of particular note

Table 5 Borreliosis and coinfection parameters from IGeneX data

\begin{tabular}{|c|c|c|c|}
\hline $\begin{array}{l}\text { Investigation parameters } \\
\text { at IGeneX }\end{array}$ & Positives & Percentage & Number \\
\hline \multicolumn{4}{|l|}{ Borrelia } \\
\hline IFA & 19 & 95 & 20 \\
\hline PCR serum & 18 & 60 & 30 \\
\hline PCR blood & 9 & 43 & 21 \\
\hline Western blot lgM & 93 & 79 & 117 \\
\hline Western blot lgG & 71 & 69 & 103 \\
\hline $\begin{array}{l}\text { IGeneX Borrelia total testing } \\
\text { positive }\end{array}$ & 146 & 58 & 252 \\
\hline $\begin{array}{l}\text { IGeneX Borrelia total testing } \\
\text { negative }\end{array}$ & 106 & 42 & 252 \\
\hline \multicolumn{4}{|l|}{ Babesia } \\
\hline Babesia duncani serology & 43 & 35 & 123 \\
\hline Babesia microti serology & 18 & 15 & 123 \\
\hline PCR Babesia & 1 & 1 & 123 \\
\hline FISH Babesia & 5 & 4 & 123 \\
\hline $\begin{array}{l}\text { IGeneX Babesia total } \\
\text { testing positive }\end{array}$ & 66 & 54 & 123 \\
\hline \multicolumn{4}{|l|}{ Bartonella } \\
\hline Bartonella sero & 23 & 19 & 122 \\
\hline Bartonella PCR & 0 & 0 & 122 \\
\hline Bartonella FISH & 6 & 5 & 122 \\
\hline $\begin{array}{l}\text { IGeneX Bartonella total } \\
\text { testing positive }\end{array}$ & 29 & 24 & 122 \\
\hline Anaplasmosis & 8 & 31 & 26 \\
\hline Ehrlichia chaffeensis & 5 & 19 & 26 \\
\hline
\end{tabular}

Abbreviations: IFA, immunofluorescent antibody assay; PCR, polymerase chain reaction; Ig, immunoglobulin; FISH, fluorescence in situ hybridization. 
Table 6 Other investigations

\begin{tabular}{llll}
\hline Other investigations & Incidence & Percentage & Number \\
\hline Abnormal CT SPECT brain from 55 requests & 40 & 73 & 55 \\
Chlamydia Pn serology positive (positive for IgG or IgM) & 48 & 32 & 152 \\
Mycoplasma sero (positive for IgG or IgM) & 44 & 25 & 174 \\
EBV sero (positive for lgG or IgM) & 140 & 89 & 158 \\
Rickettsia sero (positive for IgG or IgM) & 30 & 11 & 279 \\
Initial CD57 number assessed & 418 & & \\
Average CD57 count & 78 & & \\
\hline
\end{tabular}

Abbreviations: CT, computed tomography; SPECT, single-photon emission computed tomography; Pn, pneumonia; Ig, immunoglobulin; EBV, Epstein-Barr virus.

in the current study shows $68 \%$ monoarthropathy and $32 \%$ polyarthropathy. M. pneumoniae and Chlamydia serum PCR investigations returned positive findings in spite of negative serology for those infections in the patient series. Rickettsia infections sometimes appeared, and they routinely had neither been tested nor treated. Anecdotally, Epstein-Barr virus infection is said to be problematic in the presence of borreliosis and can flare up during treatment. Brucellosis, human herpesvirus 6, human immunodeficiency virus (HIV), leptospirosis, parvovirus, Q fever, and syphilis must be considered when determining the status of the patient, particularly in the context of immune suppression, as will be discussed.

\section{Imaging studies}

Many patients presented with prior brain $\mathrm{CT}$ scans and MRIs. When absent, a CT of the brain was ordered. In some patients who appeared to have a greater degree of neurological deficit but normal prior scanning, SPECT CT of the brain was done.

Table 7 Coinfection questionnaire assessment tool for Babesia and Bartonella

Fevers at night*

Saturated bed clothing from sweating*

Chest wall pain*

Sternum central chest pain*

Shortness of breath air hunger*

Headache at the top of the head or crown*

Dark urine*

Cough chronic and dry excessive bruising*

Vivid dreaming*

Small joint pains***

Fevers in morning**

Tender lumps under skin**

Electric shocks in limbs**

Skin stretch marks**

Glands swollen - particularly neck**

Ice pick headaches**

Irritability**

Angry outbursts**

Pain or soreness in the soles of the feet when getting out of bed**

Notes: *Babesia; **Bartonella; ***both.

\section{Laboratory assessment}

Two laboratories capable of extensive investigation of Borrelia and other TBD coinfections were used.

\section{Australian biologics}

Australian Biologics Laboratory Testing Services in Sydney, Australia was used initially in the series, and whole blood and serum analyses were performed for the detection of specific Borrelia sp. DNA using multiplex PCR for B. burgdorferi, B. afzelii, and B. garinii. Samples were analyzed in duplicate with positive and negative controls using primers $\mathrm{AB}-\mathrm{B} 1$ (proprietary to Australian Biologics) for the Borrelia 16S rRNA gene target. The thermal profile for both analyses involved incubation for 2 minutes at $50^{\circ} \mathrm{C}$, polymerase activation for 10 minutes at $95^{\circ} \mathrm{C}$, then PCR cycling for 40 cycles of 10 seconds at $95^{\circ} \mathrm{C}$, dropping to $60^{\circ} \mathrm{C}$ sustained for 45 seconds. The positive control used was an American Type Culture Collection (ATCC) B. burgdorferi genomic control. The magnitude of the PCR signal generated $(\Delta \mathrm{R})$ for each sample was interpreted as positive or negative, as compared to positive and negative controls. Validation of the assay was produced firstly by the use of external sequencing, and secondly through participation in quality assurance programs for the detection of Borrelia by PCR with Quality Control for Molecular Diagnostics (Glasgow, Scotland, UK), a joint research facility of Glasgow and Strathclyde Universities (Glasgow, Scotland, UK). Later, urine PCR analysis was added. From February 2012, some patients were also investigated by Mikrogen immunoblot for IgM and IgG, and they were also tested for borrelial T-lymphocyte transformation via the enzyme-linked immunosorbent spot test (ELISPOT). This laboratory also offered M. pneumoniae, M. fermentans, and chlamydophila PCR investigations.

\section{IGeneX}

The other laboratory principally used for borreliosis investigation was IGeneX in Palo Alto, CA, USA. IGeneX also 
offered testing for Babesia, Bartonella, A. phagocytophilum, and $E$. chaffeensis. IGeneX is a major laboratory specializing in TBDs. It is a reference laboratory recognized by the American College of Pathologists, and it is also Clinical Laboratory Improvement Amendments (CLIA), Medicare, and Medicaid approved, thus satisfying licensing requirements for testing throughout most of the United States to perform highly complex clinical testing. ${ }^{20}$ The US Food and Drug Administration and Centers for Disease Control and Prevention (CDC) oversee the performance of the CLIA. ${ }^{20}$ IGeneX has also met licensing requirements for testing in the states that require additional licensing: California; Florida; Maryland; New York; and Pennsylvania. Statements concerning laboratory performance and validation in the area of quality assurance in borreliosis testing are available on the IGeneX Website. ${ }^{21}$ Collection of sera and timely shipment was previously discussed. ${ }^{1}$ Sera were analyzed by an immunofluorescent antibody assay (IFA), followed by IgG and IgM Western blot (WB) assays. IGeneX WB uses two different strains B-31 and B-297. OspA and OspB bands are retained in the tests. ${ }^{22}$ These bands were removed from the CDC reporting criteria because they were used in the Lyme vaccine, LYMErix ${ }^{\mathrm{TM}}$. The result is a sensitivity level $>90 \%$ for the IGeneX WB test compared to $46 \%$ sensitivity for commercial tests. ${ }^{22}$ Both whole blood and sera were analyzed for the detection of specific Borrelia sp. DNA using multiplex PCR testing for B. burgdorferi-specific DNA sequences from OspA A plasmid and flagellin genes. The test is not B. burgdorferi specific, and it also detects B. afzelii, $B$. andersoni, and $B$. garinii. Simultaneously, some patients were tested for B. microti, B. duncani, A. phagocytophilum, $E$. chaffeensis, and $B$. henselae infection by IgG and IgM IFA serology, PCR, and fluorescent in situ hybridization.

\section{Other laboratories}

Several standard accredited laboratories across Australia were used for CD57 estimation and the several nonborreliosis serologies discussed within.

\section{Results}

\section{Demographic and epidemiologic factors}

The average patient's age at presentation was 41 years, with a median of 42 years and a standard deviation (SD) of 18 years. Refer to Table 1 and see Figure 1 for a rather widely splayed cumulative distribution curve. There were 310 females (62\%) in the study. Only 83 of 492 respondents (16.5\%) reported never leaving the country. Illness length in years was an average of 7.4, with a maximum of 47 years, a minimum of 0.17 years, a median of 3.0 years, and a SD of 9.5 years from a sample size of 341 . The average age of the commencement of illness was therefore 35 years, with a median of 35 years and a SD of 19 years. Thirteen patients' illness could be traced from birth or in the first year of life; six were siblings, two were from one family, and four were from another, indicating the possibility of maternal transmission. In addition, borreliosis was laboratory proven in both mothers. A recognized history of tick bites was found in 240 of 340 individuals (71\%), though the time span from bite to illness could not be reliably estimated in the majority of cases.

\section{Clinical findings}

\section{Borrelia}

Certain clinical parameters are shown in Table 2. Of the 240 individuals reporting a tick bite, 108 (22\% of the total cohort size) reported an associated rash large enough to have been considered as erythema migrans. Clinically, the diagnostic criterion for this rash is a minimum of $5 \mathrm{~cm}$.

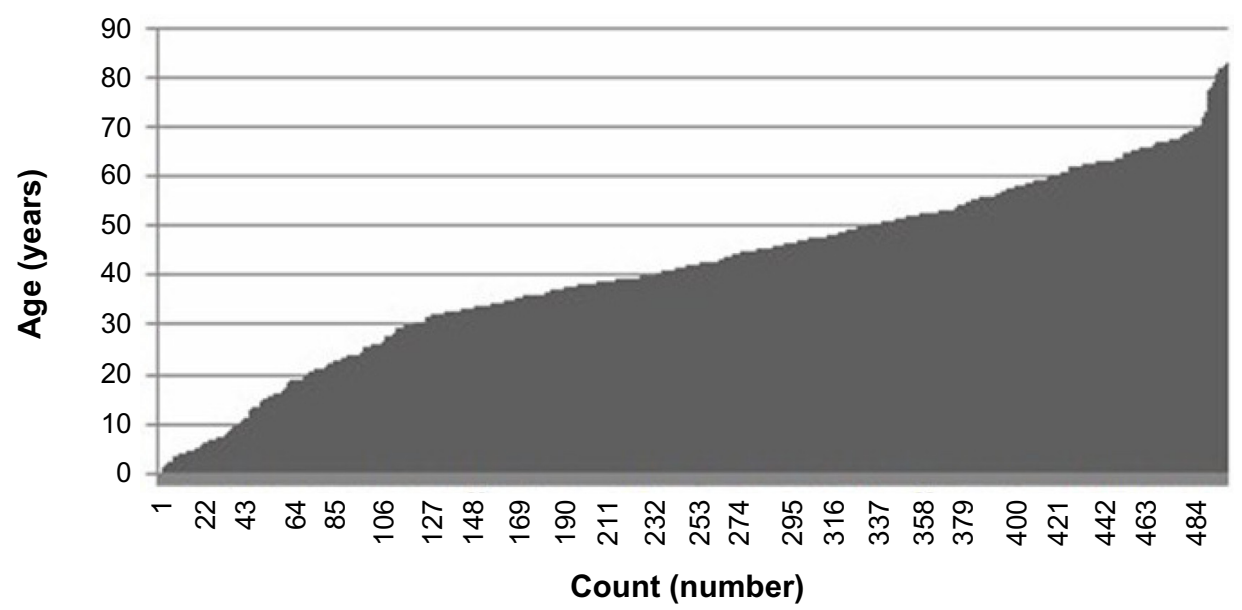

Figure I Cumulative age histogram of patients in years. 
Cranial nerve involvement was extensive and is charted as a histogram for each individual nerve (Figure 2). Cranial nerves $5,8,10$, and 11 were involved in at least $50 \%$ of respondents. It was previously proposed that when diagnosing neuroborreliosis clinically, only Borrelia, Bartonella, sarcoid, amyloid, and Guillain-Barre disease could affect more than two cranial nerves at a time, and that three nerves appear to be a crucial number in this series. ${ }^{1}$ Involvement of more than three cranial nerves was found in 296 patients (59\%), while involvement of more than two cranial nerves was found in 310 patients $(62 \%)$ (see Figures 3, 4A, and 4B). The incidence of clinically-supported borreliosis jumps dramatically at the involvement of four cranial nerves (refer to Table 8 and Figure 4). Cardiac history commonly revealed tachycardia or arrhythmia. All patients presented with electrocardiograms that were already performed to assess for heart block (a known complication of borreliosis), and to determine the baseline QTc for prescribing purposes. ${ }^{23}$ No incidence of third-degree heart block was found. Seriously delayed QTc was found in only a very small number of patients. There were some patients that were already diagnosed with postural orthostatic tachycardia syndrome (POTS), and adding suspected cases from the patient histories brought that number to 48. Many went on to have a positive tilt table test. POTS is a recognized complication of borreliosis. ${ }^{24,25}$ Neural involvement with lymphoplasmocellular infiltrates can be found in the autonomic ganglia. ${ }^{26}$ More centrally, cardiac rhythm has been shown to be controllable from the reticular formation in the midbrain, as well as from the posterior hypothalamus. ${ }^{27}$
There are no literature reports associating bartonellosis to POTS on a PubMed search. The author, however, suspects this association on the basis of Herxheimer-type reactions (which will be discussed) during initial Bartonella-targeted treatment, which is administered prior to borrelial treatment.

In addition to POTS and heart block, borreliosis can cause carditis. A PubMed search for borreliosis + carditis conducted on September 6, 2014 yielded 326 articles. Severe cardiac arrhythmia and arrest has been reported. ${ }^{28-33}$ Bartonellosis may cause carditis and also cardiac valvular disease. A PubMed search on the same date for cardiac + bartonellosis + human returned 123 articles.

In the study gastrointestinal symptoms were recorded for nausea, belching, flatus, diarrhea, constipation, and abdominal pain. Borrelia may cause bladder dysfunction. A key urinary symptom includes returning immediately after urinating but finding nothing to pass. Skin problems were reported in $11 \%$ of the cohort; they were usually widespread and often presented with itching. In $6 \%$ of patients, Morgellons could be demonstrated by skin microscopy. Morgellons has recently been closely associated with borrelial infection. ${ }^{34-37}$ There was no previous report of the incidence of Morgellons in a large borreliosis population cohort. Moreover, $11 \%$ of patients presented with small joint pain. Most often, one had to see which treatment worked best to abate this symptom to be sure of its diagnostic etiology. The two patients with large joint pains had returned from living in the US where they had contracted and undergone treatment for their infection. Using cranial nerve criteria of the involvement of more than three cranial nerves,

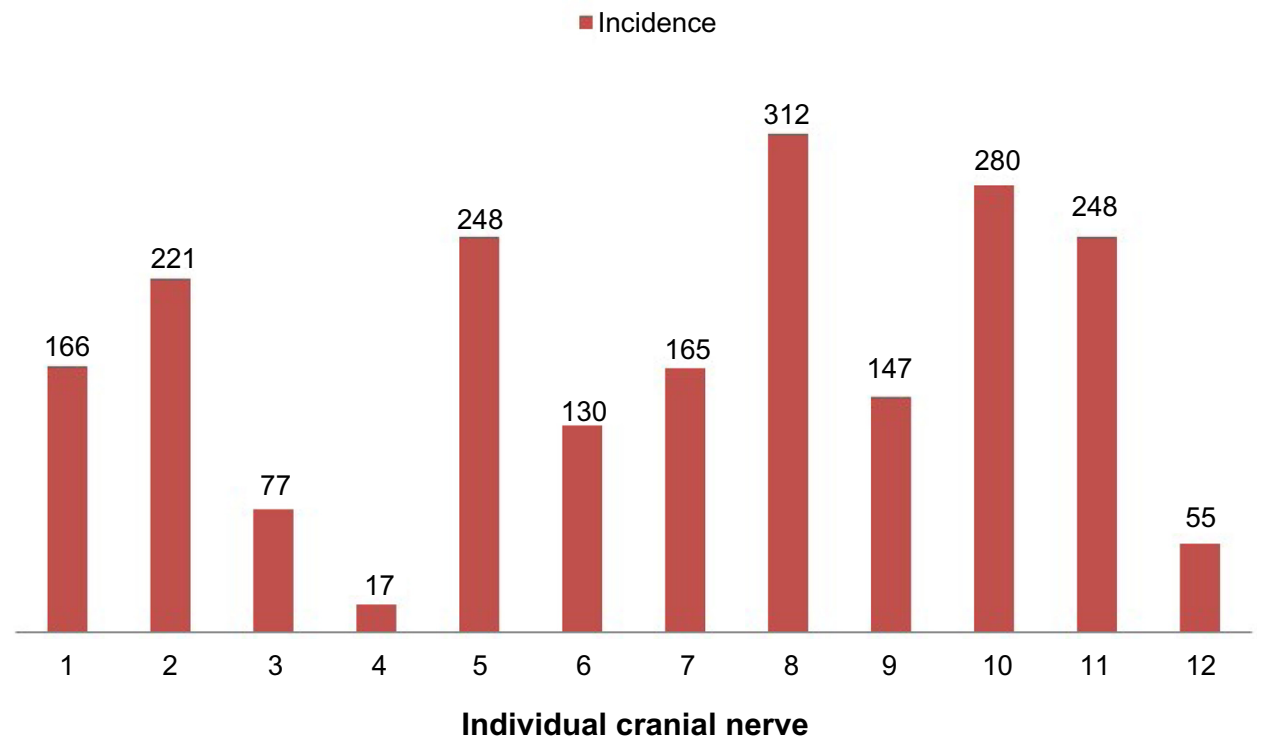

Figure 2 Histogram of the incident of involvement for each cranial nerve. 


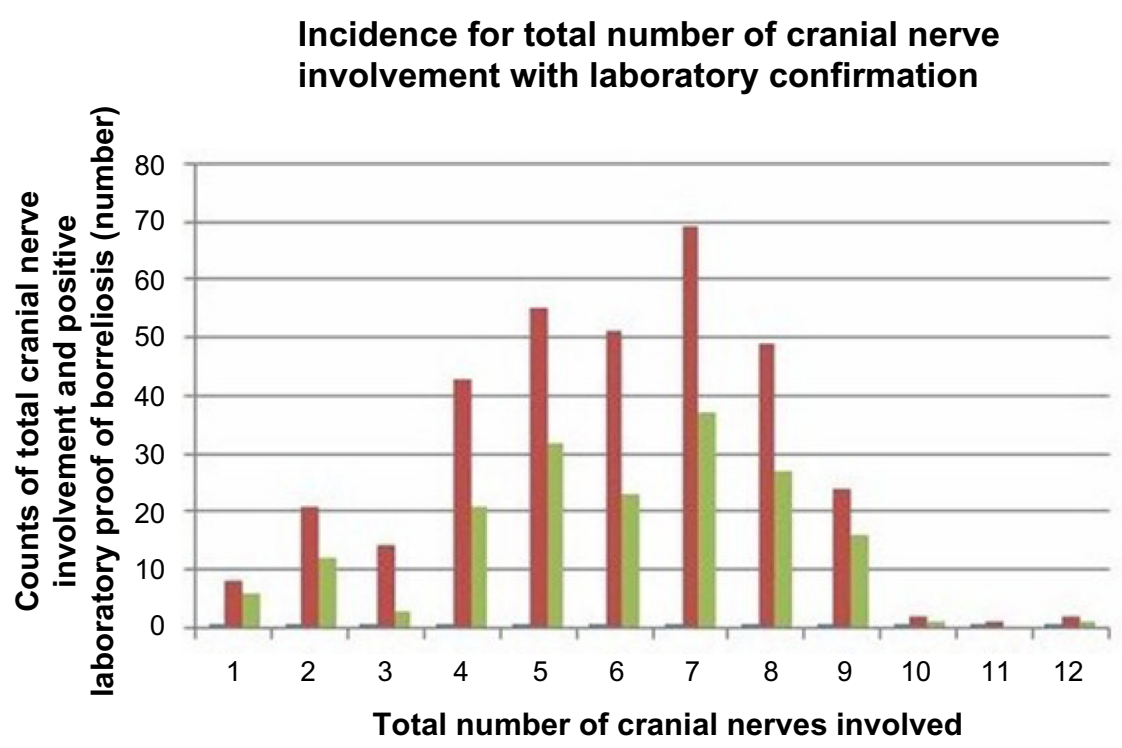

Figure 3 Histogram showing the incidence of the total number of cranial nerves involved in the dataset (red) and respective laboratory proof of borreliosis (green).

there was a clinical diagnosis of borreliosis in 296 individuals and laboratory proof in 158 of those cases.

\section{Babesiosis}

Examining the possible constellation of symptoms and signs with respect to babesiosis there were 268 cases clinically suspected and 46 laboratory proven. The babesiosis figures can be further subdivided into infection by $B$. microti (number $[\mathrm{n}]=13)$ and $B$. duncani $(\mathrm{n}=33)$, respectively, from 123 patients; four individuals had both simultaneously. These coinfections are more difficult to prove.

\section{Bartonella}

For bartonellosis, when examining the possible constellation of specific symptoms and signs, it was found that there were 240 clinically-suspected cases and 23 laboratoryproven cases. With Bartonella, we suspect that there is more than the genus $B$. henselae involved, which is the only one tested in this series. In Australia, B. koehlerae has been reported to cause human disease..$^{38}$ B. bacilliformis,
B. quintana, and B. vinsonii subspecies berkhoffii are known to cause human disease as well. ${ }^{39-42}$ Similarly, it is suspected that in Australia, there are other Babesia sp. causing human infection, and $B$. divergens is known to cause human disease. ${ }^{40}$

Combined symptomatology of the two coinfections, as well as borreliosis alone, was found in 307 (61\%) individuals. Finally, by aligning the data for clinical and laboratory factors for all three infections, only $50(10 \%)$ individuals in the entire cohort had no diagnosis. This assumes that Babesia and Bartonella, where they had occurred, were transmitted with borreliosis as a TBD. For Bartonella, this is not necessarily true, and among the case load there were two incidences of pure Bartonella infection, requiring only Bartonella-targeted treatment to achieve full recovery.

\section{Other infections}

Clinical factors for other infections were not reliably recorded in the individual files.
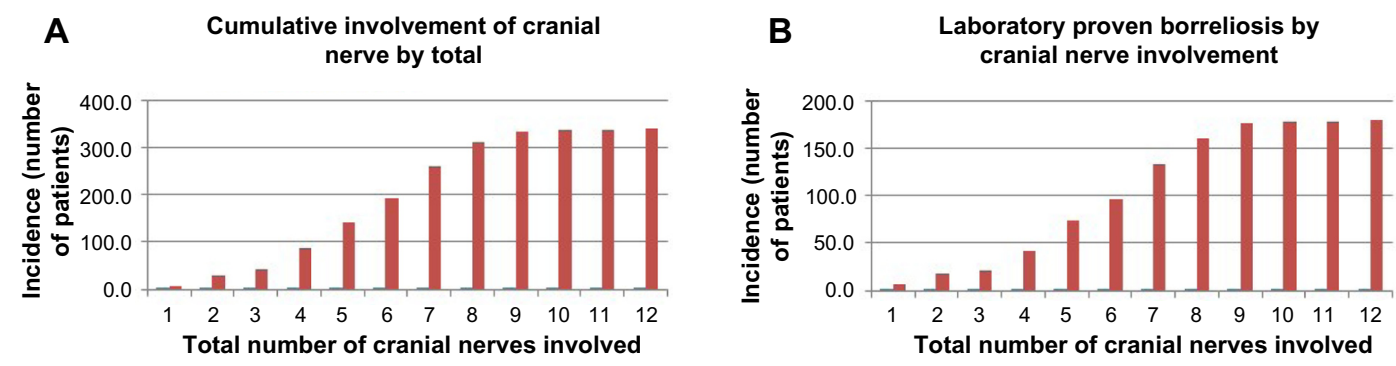

Figure 4 Cumulative involvement of the cranial nerves by total and laboratory-proven borreoliosis by cranial nerve involvement. Notes: (A) Cumulative involvement of the cranial nerves by total; (B) laboratory-proven borreoliosis by cranial nerve involvement. 
Table 8 Incidence and cumulative data for the cranial nerves with laboratory proof

\begin{tabular}{|c|c|c|c|c|c|c|c|c|c|c|c|c|}
\hline Cranial nerve & I & 2 & 3 & 4 & 5 & 6 & 7 & 8 & 9 & 10 & 11 & 12 \\
\hline Incidence of involvement & 8 & 21 & 14 & 43 & 55 & 51 & 69 & 49 & 24 & 2 & I & 2 \\
\hline Cumulative count & 8 & 29 & 43 & 86 & $14 \mid$ & 192 & 261 & 310 & 334 & 336 & 337 & 339 \\
\hline Laboratory confirmed & 6 & 12 & 3 & 21 & 32 & 23 & 37 & 27 & 16 & I & 0 & I \\
\hline Cumulative count & 6 & 18 & 21 & 42 & 74 & 97 & 134 & 161 & 177 & 178 & 178 & 179 \\
\hline
\end{tabular}

\section{Laboratory findings}

The specific methods of laboratory testing for borreliosis, bartonellosis, babesiosis, Anaplasma, and E. chaffeensis have been previously discussed. ${ }^{1}$ Results showing the incidence of the respective findings are set out in Table 4 for Australian Biologics; of note, 127 of 216 individuals were borreliosis positive (59\%). In Table 5, which presents data for IGeneX, it was found that 146 of 252 individuals were borreliosis positive (58\%). Also, IGeneX testing showed that 66 of 123 individuals were positive for Babesia (54\%), 29 of 122 were positive for Bartonella (24\%), eight of 26 were positive for anaplasmosis (31\%), and five of 26 were positive for $E$. chaffeensis infection (19\%). A review of the sequencing information of the data from Australian Biologics showed that the following species were found: $B$. burgdorfer $i$ CA382; N40; ZS7; B. garinii; B. afzelii; and B. valaisiana. The initial CD57 count was assessed in 418 individuals; the average was 78 . Three were as low as zero. Normal is considered higher than 110 .

\section{Imaging}

Invariably, CT and MRI were normal, except that occasionally an MRI brain scan would report flecks or spots of white in white matter, which were dismissed as unimportant, incidental, or of no clinical significance. SPECT CT of the brain is a valuable method for documenting the degree of neuroborreliosis. ${ }^{43}$ Fifty-five patients underwent the procedure. Some sites in Australia reliably reported the defects of this disease as neuroborreliosis. Other sites reported defects, but they dismissed these as nonspecific, in spite of the diagnosis on the request form. A review of the patient data indicated that 40 scans (73\%) showed regional defects in perfusion, as reported by radiologists, with some reports confirming neuroborreliosis.

\section{Anaplasma Ehrlichia infection case reports} Many patients were tested by serology and PCR for A. phagocytophilum and E. chaffeensis in Australia with completely negative results. Recently, the author requested this testing from IGeneX, and positive results were obtained again. Eight patients had Anaplasma infection and five had E. chaffeensis infection. Importantly though, four very sick individuals were found: one with E. chaffeensis and three with Anaplasma; these patients had never left Australia. This becomes the first case report of endemic human infection in Australia with these two bacteria. Two had low white cell counts of 3.4 and 2.9 by $10^{9} / \mathrm{L}$, respectively. All four were markedly intolerant of doxycycline and had to start $50 \mathrm{mg}$ doses, which slowly increased incrementally. All had laboratory-proven coexistent borreliosis, indirectly providing evidence for tick transmission.

\section{Rickettsial infections}

Of the 500 patients in this study, 30 of 279 (11\%) individuals had positive rickettsial serology (either IgM or IgG), demonstrating past or present infection. Allowing for some degree of cross-reactivity, this is still an appreciable number.

\section{Other parameters}

Other factors known to suppress the immune system in borrelial infection are the administration of cortisone and chemotherapy. ${ }^{44,45}$ Many coexisting infections are found in borreliosis, the incidence of which is reported in Table 6 . C. pneumoniae testing by serology was positive in 48 out of 152 individuals and by PCR in nine out of 50 individuals on serologically-negative patients. Serology detected that 44 of 174 individuals were positive for M. pneumoniae, while PCR detected that 30 out of 65 were positive among serologicallynegative patients. M. fermentans by PCR detected 18 positives out of the 69 tested. Other infections that were screened for included Q fever, brucellosis, leptospirosis, and HIV; viral encephalopathies may need to be considered. ${ }^{46}$

\section{Discussion}

Distinguishing between borreliosis and bartonellosis in a clinical setting is extremely difficult, and reliance on specific Bartonella symptoms is important. It appears that both diseases often coexist and are tick-borne in Australia. A comparison can be made with a recent publication by Berghoff ${ }^{47}$ on the differential diagnoses of these infections. There is a wide age distribution and, importantly, an extensive delay in the recognition and diagnosis of neuroborreliosis. This could be improved with detection of cranial nerve 
symptoms and deficits. The cumulative histogram in Figure 4 shows, firstly, an exponential increase in the clinical diagnosis of neuroborreliosis with increasing cranial nerve involvement and, secondly, the number of positive laboratory findings that rise correspondingly with the involvement of four cranial nerves. The histograms show a sigma curve, which is virtually identical for both a clinical diagnosis versus a laboratory-supported diagnosis. When examining the figures for a clinical diagnosis, the $\mathrm{X}$-axis simply represents an ordinal increase in count and the gradient $(\tan \theta)$ is simply the difference between each Y-axis count: 14 for 3; 43 for $4 ; 55$ for 5; 51 for 6; and 69 for 7, before falling again as the sigma curve flattens. Linear regression analysis of the data yielded a coefficient of 0.999485 . It is proposed that the involvement of three cranial nerves is thus a critical number, which could pivot the diagnosis of clinical borreliosis or bartonellosis in either direction; however, the involvement of four or more cranial nerves correlates well with a clinical diagnosis of either borreliosis or bartonellosis.

The ELISA/IFA/WB controversy has been discussed before. ${ }^{1}$ The current $\mathrm{CDC}$ position statement on Lyme disease case surveillance can be found on the CDC Website. ${ }^{48}$ It has been acknowledged by the CDC that there is a large burden of disease that can only be diagnosed clinically. Specifically, the CDC states the following "For purposes of surveillance":48

Nervous system. Any of the following, alone or in combination: lymphocytic meningitis; cranial neuritis, particularly facial palsy (may be bilateral); radiculoneuropathy; or, rarely, encephalomyelitis.

In this report, there is very close concordance between the sensitivities of IGeneX and Australian Biologics running at $58 \%$ and $59 \%$ of the total tested, respectively. In Europe borreliosis is associated sometimes with acrodermatitis chronica atrophicans which is caused by $B$. afzellii. In this series, only two patients had acrodermatitis chronica atrophicans and one had never traveled outside Australia. Diagnosing the correct infections to prioritize appropriate treatment is essential. It is important to clear coinfections before treating infections caused by Borrelia. ${ }^{15,16}$ Treating Borrelia infections first can, in fact, make the patient deteriorate further. ${ }^{15,16}$ This is supported by observation of the emergence of the specific coinfection symptoms of bartonellosis or babesiosis during borreliosis treatment. Not only must the two coinfections be cleared, but any of the other current infections should also be treated, and sometimes this can be viral. A quick check on the CD4 count will tell if the patient is fighting a viral load. Almost surprisingly, the incidence of HIV positivity in the cohort was zero where tested. As can be seen by the data presented, pure borrelial infection is not common in Australia, and consideration must be given to a host of infections when assessing TBD. The data were reliable for this finding from patient 300 onwards. In this subset, 17 (8.5\%) patients had pure borreliosis confirmed by testing, and no clinical suspicion or laboratory proof of coinfection was observed. Fifty patients $(10 \%)$ could not be diagnosed as having one of the three key infections in the series, either clinically or by investigation. It is highly concerning that $11 \%$ of patients had positive rickettsial serology with a protracted disease complex and had never been tested for this infection.

White matter flecks seen on MRI in proven neuroborreliosis can be a result of that infection. ${ }^{49-52}$ Further, Kanekar and Devgun ${ }^{53}$ state that in neuroborreliosis,

The most common abnormality seen on MR is multiple bilateral periventricular and/or subcortical foci of $\mathrm{T} 2$ prolongation. These findings usually mimic MS (multiple sclerosis); however, multiple enhancing cranial nerves (third, fifth, and seventh cranial nerve), nerve root, or meningeal enhancement may favor Lyme over MS. ${ }^{43,53-56}$

The incidence of SPECT abnormality in neuroborreliosis was $75 \%$ in one study. ${ }^{43}$ The current study's data of 40 out of 55 scans $(73 \%)$ appear to conform to those findings if the reported areas of reduced perfusion are considered as an abnormal scan. CD57 is a measure of immune suppression in the presence of borreliosis $;{ }^{57}$ normal is considered a value $\geq 110$ cells $/ \mathrm{mm}^{3}$ using the Beckman Coulter antibody (catalog A74779; Beckman Coulter, Inc., Brea, CA, USA), with $<60$ considered very significant borreliosis. The potential diversity of tick-borne infections was recently enumerated at 237 pathogens in a recent study of Ixodes perscultatus in the People's Republic of China; ${ }^{58}$ this has modeling applications for Australia.

\section{Jarisch-Herxheimer reaction}

This reaction is well described in the literature, but particularly well by Horowitz. ${ }^{16}$ In summary, the breakdown products of the cellular components of Borrelia, Babesia, and Bartonella (in particular, the cell wall products of Borrelia) produce a temporary IL storm of IL-1, IL-6, and TNF- $\alpha$. The effect is similar to having viral influenza, which induces the same storm, plus a patient will experience some of the symptom set associated with their own disease complex. The reaction can be very severe in some individuals and is dependent upon bacterial load versus treatment dosage. In treatment, a balance is sought between what a patient can 
comfortably endure using as many remedial measures as possible to relieve distress, and sufficient therapy to be effective against the disease being targeted.

\section{The vectors}

Recently Mayne et al have unequivocally demonstrated evidence for Ixodes holocyclus, the paralysis tick, as a vector for human borreliosis. ${ }^{59}$ The vector is found along the entire eastern seaboard of the continent and across into central Victoria. Other vectors need to be sought in this region and across Australia.

\section{Conclusion}

Neuroborreliosis can affect large numbers of cranial nerves. Herewith, data were presented demonstrating that a thorough search for symptoms and signs of cranial nerve abnormality can clinically pinpoint neuroborreliosis and/or bartonellosis when more than three nerves are involved. The total results highlight an underestimated set of TBD in Australia that requires further research and evaluation. Borreliosis is protean in its manifestation and difficult to treat if protracted. Those in the medical profession in Australia need to be alert to the possibility of detecting this disease and its associated coinfections early to initiate effective short-lasting treatment, thus preventing a cascade into severe chronic borreliosis, which can be devastating in all aspects of life.

\section{Acknowledgments}

The author thanks the Southern Analytics Team: Kosta Patsan; Alex Patsan; Daphne Patsantzopoulos; Richard Jennings; Irene Pappas; Costa Pappas; Emily Miklovic; and Anna Farmaki for their arduous work in preparation of the data; as well as Marianne Middelveen for manuscript review.

\section{Disclosure}

From 2014 the author has served as a medical adviser at Australian Biologics as a free service. The author reports no other conflicts of interest in this work.

\section{References}

1. Mayne PJ. Emerging incidence of Lyme borreliosis, babesiosis, bartonellosis, and granulocytic ehrlichiosis in Australia. Int J Gen Med. 2011;4:845-852.

2. Gürtler L, Blümel J, Burger R, et al. Arbobacteria - pathogens transmittable by arthropods. Transfus Med Hemother. 2008;35(5):374-390.

3. Senanayake SN, Paparini A, Latimer M, et al. First report of human babesiosis in Australia. Med J Aust. 2012;196(5):350-352.

4. Paparini A, Senanayake SN, Ryan UM, Irwin PJ. Molecular confirmation of the first autochthonous case of human babesiosis in Australia using a novel primer set for the beta-tubulin gene. Exp Parasitol. 2014;141:93-97.
5. Soloski MJ, Crowder LA, Lahey LJ, Wagner CA, Robinson WH, Aucott JN. Serum inflammatory mediators as markers of human Lyme disease activity. PLoS One. 2014;9(4):e93243.

6. Mattsson N, Bremell D, Anckarsäter R, et al. Neuroinflammation in Lyme neuroborreliosis affects amyloid metabolism. BMC Neurol. 2010;10:51.

7. Miklossy J. Chronic inflammation and amyloidogenesis in Alzheimer's disease - role of Spirochetes. J Alzheimers Dis. 2008;13(4):381-391.

8. Moklossy J, Khalili K, Gern L, et al. Borrelia burgdorferi persists in the brain in chronic lyme neuroborreliosis and may be associated with Alzheimer disease. J Alzheimers Dis. 2004;6(6):639-649; discussion 673-681.

9. Ishihara M, Ohno S, Ono H, et al. Seroprevalence of anti-Borrelia antibodies among patients with confirmed sarcoidosis in a region of Japan where Lyme borreliosis is endemic. Graefes Arch Clin Exp Ophthalmol. 1998;236(4):280-284.

10. Ishihara M, Ishida T, Isogai E, et al. Detection of antibodies to Borrelia species among patients with confirmed sarcoidosis in a region where Lyme disease is nonendemic. Graefes Arch Clin Exp Ophthalmol. 1996;234(12):770-773.

11. Palimeris G, Marcomichelakis N, Konstantinidou V, Trakaniari AN Intermediate uveitis: what is the natural course of the disease and its relationship with other systemic diseases? Eur J Ophthalmol. 1994;4(4): 223-227.

12. Li QD, Hua B, Wang FM. [The diagnostic value of anti-BB-antibody estimation in sarcoidosis]. Zhonghua Jie He He Hu Xi Za Zhi. 1994; 17(3):162-164, 190-191. Chinese.

13. Hua B, Li QD, Wang FM. [Borrelia burdorferi may be the causal agent of sarcoidosis]. Zhonghua Nei Ke Za Zhi. 1992;30(10):631-633, 659. Chinese.

14. Burrascano JJ Jr. Advanced Topics in Lyme Disease: Diagnostic Hints and Treatment Guidelines for Lyme and Other Tick Borne Illnesses. 16th ed. Bethesda, MD: International Lyme and Associated Diseases Society; 2008. Available from: http://www.lymenet.org/BurrGuide200810.pdf. Accessed September 7, 2011.

15. Harris S. Lyme disease: considerations in diagnosis and management Poster presented at: International Lyme and Associated Diseases Society conference; October 15-17, 2010; Jersey City, NJ USA.

16. Horowitz R. Why Can't I Get Better? Solving the Mystery of Lyme and Chronic Disease. 1st ed. New York, NY: St Martin's Press; 2013.

17. Hildebrandt A, Gray JS, Hunfeld KP. Human babesiosis in Europe: what clinicians need to know. Infection. 2013;41(6):1057-1072.

18. Hunfeld KP, Hildebrandt A, Gray JS. Babesiosis: recent insights into an ancient disease. Int J Parasitol. 2008;38(11):1219-1237.

19. Zeidler H, Hudson AP. New insights into Chlamydia and arthritis. Promise of a cure? Ann Rheum Dis. 2014;73(4):637-644.

20. Centers for Disease Control and Prevention [webpage on the Internet]. Clinical Laboratory Improvement Amendments (CLIA). Atlanta, GA Centers for Disease Control and Prevention. Available from: http:// wwwn.cdc.gov/CLIA/Default.aspx. Accessed September 6, 2014.

21. IGeneX, Inc. Quality Assurance and Proficiency Statement. Palo Alto, CA: IGene X, Inc.; 2010. Available from: http://IGeneX.com/files/ QA_PACKAGE_2010.pdf. Accessed September 6, 2014.

22. Shah JS, Du Cruz I, Narciso W, Lo W, Harris NS. Improved clinical sensitivity for detection of antibodies to Borrelia burgdorferi by Western blots prepared from a mixture of two strains of B. burgdorferi, 297 and B31, and interpreted by in-house criteria. European Infect Dis. 2010;4:56-60.

23. Chauhan V, Chauhan N, Chauhan CG, Vaid M. A young healthy male with syncope and complete heart block. Scott Med J. 2013;58(2): e13-e17.

24. Noyes AM, Kluger J. A tale of two syndromes: Lyme disease preceding postural orthostatic tachycardia syndrome. Ann Noninvasive Electrocardiol. Epub May 15, 2014.

25. Kanjwal K, Karabin B, Kanjwal Y, Grubb BP. Postural orthostatic tachycardia syndrome following Lyme disease. Cardiol J. 2011;18(1): 63-66. 
26. Duray PH. Histopathology of clinical phases of human Lyme disease. Rheum Dis Clin North Am. 1989;15(4):691-710.

27. Manning JW. Central nervous system control of cardiac rhythm. Cardiology. 1976;61(1):7-19.

28. Centers for Disease Control and Prevention (CDC). Three sudden cardiac deaths associated with Lyme carditis - United States, November 2012July 2013. MMWR Morb Mortal Wkly Rep. 2013;62(49):993-996.

29. Hagen K. [Risk of infections among orienteers]. Tidsskr Nor Laegeforen. 2009;129(13):1326-1328. Norwegian.

30. Franck $H$, Wollschläger $H$. [Lyme carditis and symptomatic sinus node dysfunction]. Z Kardiol. 2003;92(12):1029-1032. German.

31. Weissman K, Jagminas L, Shapiro MJ. Frightening dreams and spells: a case of ventricular asystole from Lyme disease. Eur J Emerg Med. 1999;6(4):397-401.

32. Rosenfeld ME, Beckerman B, Ward MF, Sama A. Lyme carditis: complete $\mathrm{AV}$ dissociation with episodic asystole presenting as syncope in the emergency department. J Emerg Med. 1999;17(4):661-664.

33. Reimers CD, de Koning J, Neubert U, et al. Borrelia burgdorferi myositis: report of eight patients. J Neurol. 1993;240(5):278-283.

34. Middelveen MJ, Burugu D, Poruri A, et al. Association of spirochetal infection with Morgellons disease. F1000Res. 2013;2:25.

35. Middelveen MJ, Mayne PJ, Kahn DG, Stricker RB. Characterization and evolution of dermal filaments from patients with Morgellons disease. Clin Cosmet Investig Dermatol. 2013;6:1-21.

36. Stricker RB, Middelveen MJ. Morgellons disease: more questions than answers. Psychosomatics. 2012;53(5):504-505; author reply 505-506.

37. Middelveen MJ, Stricker RB. Filament formation associated with spirochetal infection: a comparative approach to Morgellons disease. Clin Cosmet Investig Dermatol. 2011;4:167-177.

38. Mascarelli PE, Iredell JR, Maggi RG, Weinberg G, Breitschwerdt EB. Bartonella species bacteremia in two patients with epithelioid hemangioendothelioma. J Clin Microbiol. 2011;49(11):4006-4012.

39. Chomel BB, Kasten RW, Williams C, et al. Bartonella endocarditis: a pathology shared by animal reservoirs and patients. Ann N Y Acad Sci. 2009;1166:120-126.

40. Bonnet S, Michelet L, Moutailler S, et al. Identification of parasitic communities within European ticks using next-generation sequencing. PLoS Negl Trop Dis. 2014;8(3):e2753.

41. Prutsky G, Domecq JP, Mori L, et al. Treatment outcomes of human bartonellosis: a systematic review and meta-analysis. Int $J$ Infect Dis. 2013;17(10):e811-e819.

42. Angelakis E, Raoult D. Pathogenicity and treatment of Bartonella infections. Int J Antimicrob Agents. 2014;44(1):16-25.

43. Donta ST, Noto RB, Vento JA. SPECT brain imaging in chronic Lyme disease. Clin Nucl Med. 2012;37(9):e219-e222.

44. Pachner AR, Amemiya K, Bartlett M, Schaefer H, Reddy K, Zhang WF. Lyme borreliosis in rhesus macaques: effects of corticosteroids on spirochetal load and isotype switching of anti-borrelia burgdorferi antibody. Clin Diagn Lab Immunol. 2001;8(2):225-232.
45. Kollikowski HH, Schwendemann G, Schulz M, Wilhelm H, Lehmann HJ. Chronic borrelia encephalomyeloradiculitis with severe mental disturbance: immunosuppressive versus antibiotic therapy. $J$ Neurol. 1988;235(3):140-142.

46. Kennedy PG. Viral encephalitis: causes, differential diagnosis, and management. J Neurol Neurosurg Psychiatry. 2004;75 Suppl 1: i10-i15.

47. Berghoff W. Chronic Lyme disease and co-infections: differential diagnosis. Open Neurol J. 2012;6:158-178.

48. Centers for Disease Control and Prevention [webpage on the Internet]. Lyme disease (Borrelia burgdorferi) 2011 case definition: CSTE position statement(s). Atlanta, GA: Centers for Disease Control and Prevention; 2011. Available from: http://wwwn.cdc.gov/NNDSS/script/casedef. aspx?CondYrID=752\&DatePub=1/1/2011\%2012:00:00\%20AM. Accessed September 6, 2014.

49. Fallon BA, Keilp J, Prohovnik I, Heertum RV, Mann JJ. Regional cerebral blood flow and cognitive deficits in chronic lyme disease. J Neuropsychiatry Clin Neurosci. 2003;15(3):326-332.

50. Fallon BA, Lipkin RB, Corbera KM, et al. Regional cerebral blood flow and metabolic rate in persistent Lyme encephalopathy. Arch Gen Psychiatry. 2009;66(5):554-563.

51. Morgen K, Martin R, Stone RD, et al. FLAIR and magnetization transfer imaging of patients with post-treatment Lyme disease syndrome. Neurology. 2001;57(11):1980-1985.

52. Matera G, Labate A, Quirino A, et al. Chronic neuroborreliosis by B. garinii: an unusual case presenting with epilepsy and multifocal brain MRI lesions. New Microbiol. 2014;37(3):393-397.

53. Kanekar S, Devgun P. A pattern approach to focal white matter hyperintensities on magnetic resonance imaging. Radiol Clin North Am. 2014;52(2):241-261.

54. Agosta F, Rocca MA, Benedetti B, Capra R, Cordioli C, Filippi M. MR imaging assessment of brain and cervical cord damage in patients with neuroborreliosis. AJNR Am J Neuroradiol. 2006;27(4):892-894.

55. Vanzieleghem B, Lemmerling M, Carton D, et al. Lyme disease in a child presenting with bilateral facial nerve palsy: MRI findings and review of the literature. Neuroradiology. 1998;40(11):739-742.

56. Köchling J, Freitag HJ, Bollinger T, Herz A, Sperner J. Lyme disease with lymphocytic meningitis, trigeminal palsy and silent thalamic lesion. Eur J Paediatr Neurol. 2008;12(6):501-504.

57. Stricker RB, Winger EE. Decreased CD57 lymphocyte subset in patients with chronic Lyme disease. Immunol Lett. 2001;76(1):43-48.

58. Zhang XC, Yang ZN, Lu B, Ma XF, Zhang CX, Hu HJ. The composition and transmission of microbiome in hard tick, Ixodes persulcatus, during blood meal. Ticks Tick Borne Dis. 2014;5(6):864-870.

59. Mayne P, Song S, Shao R, Burke J, Wang Y, Roberts T. Evidence for Ixodes holocyclus (Acarina: Ixodidae) as a Vector for Human Lyme Borreliosis Infection in Australia. J Insect Sci. 2014;14(1):271.
International Journal of General Medicine

\section{Publish your work in this journal}

The International Journal of General Medicine is an international, peer-reviewed open-access journal that focuses on general and internal medicine, pathogenesis, epidemiology, diagnosis, monitoring and treatment protocols. The journal is characterized by the rapid reporting of reviews, original research and clinical studies across all disease areas.

\section{Dovepress}

A key focus is the elucidation of disease processes and management protocols resulting in improved outcomes for the patient.The manuscript management system is completely online and includes a very quick and fair peer-review system. Visit http://www.dovepress.com/ testimonials.php to read real quotes from published authors. 